Article

\title{
The Environmental Costs of Photovoltaic Power Plants in South Korea: A Choice Experiment Study
}

\author{
Hee-Jong Yang ${ }^{1}$, Seul-Ye Lim $^{2}$ and Seung-Hoon Yoo ${ }^{2, *}$ \\ 1 Graduate Program in Technology Policy, College of Engineering, Yonsei University, 50 Yonsei-Ro, \\ Seodaemun-Gu, Seoul 03722, Korea; heejong.yang@yonsei.ac.kr \\ 2 Department of Energy Policy, Graduate School of Energy \& Environment, Seoul National University of \\ Science \& Technology, 232 Gongreung-Ro, Nowon-Gu, Seoul 01811, Korea; sylim@seoultech.ac.kr \\ * Correspondence: shyoo@seoultech.ac.kr; Tel.: +82-2-970-6802
}

Received: 31 August 2017; Accepted: 25 September 2017; Published: 30 September 2017

\begin{abstract}
The photovoltaic (PV) power supplies renewable and sustainable electricity without greenhouse gases and air pollutants emissions. However, the potential environmental impacts caused by PV power plants can negatively affect both the ecosystem and human life. Thus, the environmental costs arising from the PV power plants should be measured and the efforts to reduce them should be made. To this end, this article seeks to assess the environmental costs of PV power plants using a choice experiment (CE). Four attributes chosen for this purpose are habitat loss, landscape destruction, hazardous materials, and light pollution. The trade-offs between each attribute and price were successfully assessed in the CE survey of 1000 South Korean respondents. The environmental costs of a one percentage point increase in habitat loss, landscape destruction, hazardous materials, and light pollution caused by PV power plants are estimated to be KRW 135 (USD 0.12), 53 (0.05), 122 (0.11), and $158(0.14)$, respectively, per household per month. The findings can provide policymakers with useful information for both evaluating and planning the PV power plant-related policies.
\end{abstract}

Keywords: environmental costs; photovoltaic power; choice experiment; willingness to pay; multinomial logit model

\section{Introduction}

Consumption of fossil fuels has caused various environmental issues, such as air pollutants and greenhouse gas (GHG) emissions. Therefore, promoting the use of renewable energy has become an important national energy policy issue in South Korea. The ratio of renewable energies to total generation was $6.6 \%$ in 2015. The South Korean government is planning to generate $20 \%$ of electricity consumed in the country through fuel cell and renewable energies until 2030. In fulfilling the plan, photovoltaic (PV) power plants will play a crucial role since there are scarce sites suitable for wind power generation in South Korea. For example, the capacity of PV power plants will increase from 5 GW in 2016 to $37 \mathrm{GW}$ in 2030. The total capacity of power plants in 2030 is expected to be $132 \mathrm{GW}$. Consequently, the PV power plants will account for about $28 \%$ of the total generation capacity in 2030.

The supply chain of South Korean PV industry is made up of five poly silicon-producing companies, 10 ingot and wafer-producing companies, five solar cell-producing companies, $19 \mathrm{PV}$ module-producing companies, and a number of PV system installation companies. The production capacities of poly silicon, wafer, solar cell, and solar module are 96,000 tons, $2830 \mathrm{MW}, 2145 \mathrm{MW}$, and $4280 \mathrm{MW}$, respectively, as of 2015. There are three representative companies in the PV industry. They are Hanwha Q CELLS, Hanwha SolarOne, and OCI. Hanwha Q CELLS is a total solar power solution provider with the world's largest cell production with its cell capacity of 3280 MW. Hanwha SolarOne is one of the top $10 \mathrm{PV}$ module manufacturers in the world. OCI is a major supplier of solar 
and semiconductor grade polysilicon with a total annual production capacity of 42,000 tons. They have developed businesses mainly in Europe, North America, Asia, South America, Africa, and the Middle East. However, they are expected to augment the investments on domestic markets because recently the South Korean government officially announced the plan of dramatically increasing the PV power generation.

PV power may be regarded as a perfect energy source, but it is disclosed that PV power plants have some negative repercussion for the environment and human health through life cycle assessment [1-3]. First, PV power plants can damage land and ecosystems. Large-scale PV power plants arouse concerns about land degradation and habitat loss. The major influence on the wildlife and habitat is due to land seizure by the power plant itself [4]. According to the United States Department of Energy [5], the power plant is typically enclosed by a fence and interferes with animal movement.

Second, PV power plants can spoil scenic beauty [1,6]. There is also a view that the colorful PV plants can be used to decorate beautiful scenery. However, the condition in South Korea is different from those of other countries. In particular, South Korea is densely populated, and more than 70 percent of the nation's land is mountainous. Therefore, it cannot be helped that many PV panels are installed on the mountainside, cutting off trees and soil. This situation is ruining the natural landscape and causing serious civil petitions [2].

Third, there is the negative effect of hazardous materials during manufacture and operation. The PV cell manufacturing process includes a number of hazardous materials, most of which are used to clean and purify the semiconductor surface. These chemicals, similar to those used in the general semiconductor industry, include hydrochloric acid, sulfuric acid, nitric acid, hydrogen fluoride, 1,1,1-trichloroethane, and acetone [7]. In addition, thin-film PV cells contain a number of more toxic materials than those used in traditional silicon photovoltaic cells, including gallium arsenide, copper-indium-gallium-diselenide, and cadmium-telluride [8]. If not handled and disposed of properly, these materials could pose serious environmental or public health threats. Moreover, the coolant liquids include nitrates, nitrites, sulphites, sulphates, glycol and chromates. Except for the normal use, there may be the risk of accidental water pollution through leaks of the coolant liquids [6]. Therefore, PV panels can be harmful to health as well as to the soil or groundwater.

Finally, solar panels are also a source of light pollution [9-11]. Light pollution is excessive and inappropriate artificial light. The four components of light pollution are often combined and may overlap; they include urban sky glow, light trespass, glare and clutter. Increased urban sky glow is responsible for the disappearance of the Milky Way from our night skies. Light trespass contributes to a loss of natural darkness. Wildlife, too, is harmed by the unnecessary brightening of the night. From newly hatched sea turtles to migrating birds, fish, frogs, salamanders, and lightning bugs, artificial night lighting disrupts the cycles of nocturnal creatures in potentially devastating ways. Direct glare from improperly shielded fixtures is often blinding [12,13]. The redundant lighting found in many urban centers results in a clutter of lights that contribute to sky glow, trespass, and glare while destroying the ambiance of our nighttime environment. Light pollution affects every citizen. It is a serious environmental concern that wastes money and resources while jeopardizing wildlife, our environment, health, and human heritage.

Recently, there has been a growing call for the renewable energy management systems to establish sustainable development and a zero-waste society. Thus, it is easy to search many previous studies that examined public willingness to pay (WTP) for PV power plant employing stated preference techniques such as contingent valuation (CV) (e.g., [14-16]) and a choice experiment (CE) (e.g., [17-20]). On the other hand, no study about the environmental cost caused by PV plants using CE or CV has been found in the literature. However, there is a similar study of WTP for mitigating the environmental damage of tidal power plant construction using CE (e.g., [21]). It is important to consider negative impacts of renewable energy, in particular, to be analyzed quantitatively. To this end, we try to apply a CE with four attributes of environmental damages, such as habitat loss, landscape destruction, hazardous 
materials, and light pollution. Furthermore, we anticipate this study can provide policymakers and researchers with a promising opportunity to explore environmental cost caused by PV power plants.

Therefore, the purpose of this study is to measure the environmental costs of PV power plants using a specific case of South Korea. The remainder of the paper is divided into four parts. Section 2 explains the CE approach adopted in this paper and discusses the methodological issues. Section 3 presents the theoretical and statistical models used to obtain the WTP for mitigating negative effect caused by PV plants. Section 4 includes the estimation results and the environmental cost of certain scenarios. The final section presents some concluding remarks.

\section{Methodology}

\subsection{CE Approach}

Costs and benefits are the same as both sides of a coin. That is to say, we can assess the environmental costs through estimating WTP for mitigating the environmental damage. In this study, we estimate WTP for mitigating damage of PV power plants, and it would be interpreted as the environmental cost of PV power plants. Moreover, we calculate marginal WTP (MWTP) and measure the environmental cost of a one unit increase in each attribute using the $\mathrm{CE}$ approach.

$\mathrm{CE}$ is a multi-attribute preference-driven technique that is widely used to assess new products before introduction and to plan new markets for well-known products [22-24]. When compared to other evaluation methods, CE is good at evaluating environmental goods with multiple characteristics [25-28]. The contingent valuation method also uses a survey to estimates people's utilities and is popular in estimating the economic value of non-market goods, while CE measures goods with several distinguishing characteristics and has often been used as an alternative to the contingent valuation method.

$\mathrm{CE}$ is an attractive approach. First of all, when measuring the value of each attribute embedded in an environmental good, CE gives the results in an easy and simple way. This is a powerful quality for policymakers; in most cases policymaking is more related to changing attribute levels than to varying the level of the good as a whole [29]. Secondly, it shows the relationships among several environmental attributes or whether there can be trade-offs between environmental and non-environmental elements. This trade-off process may encourage respondents to introspect their responses; it also facilitates checks of the consistency of response patterns [30]. In CE, as respondents are asked several times with different questionnaire, it is possible to check the consistency of response patterns. In addition, as the CE approach does not ask respondents for their WTPs, it reduces the number of protestant responses, especially with respect to those who are either against increases in payment burden or unwilling to accept environmental degradation in return for payment. It also increases the amount of information that is obtained from each respondent, thus reducing the required sample, and hence reducing the costs of the survey [21].

Choice-based approaches can be divided into three methods: contingent choice, contingent ranking, and contingent rating [31]. The contingent choice method shows the respondent a questionnaire, which consists of two or more hypothetical alternatives, and obtains the respondent's preferred decision, whereas the other two methods require the respondent to record his or her opinion on each alternative. In a contingent ranking survey the respondents rank their preferences from the most-preferred to the least-preferred [32,33]. The contingent rating method has different answers: the respondents must give their preference for, or rate the importance of, the alternatives by giving each a minimum of one point and a maximum of ten points.

Among the three CE methods, we applied the contingent choice method because choosing one alternative is simpler than ranking or rating a list of alternatives. It would have been burdensome for the interviewees to consider all the alternatives in every choice set, and this would have led to insincere replies. Reducing the burden on respondents helps them to express their preferences or opinions sincerely. We tried to take advantage of this as data reliability is essential to questionnaire analysis. 
A choice system is also similar to people's behavior in the real world. Most purchase behavior is the selection of one item from two or more similar items, or the selection of the best item. Consumers rarely rank all items or rate all of them, as this is irritating and makes them likely to give up answering all the questions or to answer them carelessly, which would generate erroneous study data. Thus, we used a contingent choice method in order to reduce respondents' resistance and the number of refusals. Although the CE format was unfamiliar to the interviewees, they easily understood how to respond to the questionnaire: answering the questionnaire is like their usual activities.

\subsection{Attributes}

This study assumes various hypothetical policies which consist of multiple attributes and estimates of the environmental costs of PV power plants by assessing these hypothetical policies. To identify the important attributes of the environmental damage that is caused by the PV power plants, we selected a preliminary set of attributes that was derived by extensive literature reviews. Then, we reviewed and revised the attributes through extensive interviews with policy analysts, researchers, and academics. The final attributes were selected based on the five criteria listed below.

First, the attributes should be independent or nearly independent of one another. Second, there should only be a few attributes-preferably not more than six-because otherwise trade-offs become difficult to understand; further, trade-offs cannot be displayed to respondents in a comprehensible form if there are too many attributes. Third, attributes should be describable through a combination of simple explanations and visual instruments such as photographs, charts, and pictures. Fourth, attributes should be scientifically meaningful. Fifth, the change in the level of attributes should influence respondents' utility and relate to their reasons for having WTP to mitigate the environmental damage [21,34].

By using these five screening criteria, we identified five attributes. These include the habitat loss, landscape destruction, hazardous materials, light pollution, and price. The price attribute is defined as the additional monthly electricity bill per household, which is likely to be familiar to respondents in general. The price refers to the cost involved in reducing the environmental damage caused by PV power plants. We decided the levels of the price attribute through a pre-test. In this study, a pre-test was conducted by asking a focus group (30 persons) how much she/he is willing to pay for alleviating the environmental damage. Then the upper and lower bounds were determined based on the distribution of the focus group's WTP. The lower bound is zero and the upper bound is KRW 7000.

The levels of four attributes (except for price) were refined through using a focus group to discuss respondents' understanding of and reaction to them, and was set to prevent equidistance. This focus group's input helped us to identify the most important and meaningful levels. The highest level represents the worst environmental degradation scenario and the lowest level means the status quo level. In the case of light pollution, we followed the Illuminating Engineering Society of North America definitions.

One of the most important things in the survey is to clearly identify the differences between the each level. Therefore, our CE survey was conducted using face-to-face in-person interviews. We wished to convey a large amount of explanatory information to the respondents on definition and character of each attribute and present visual cards describing environmental impacts of each attribute level. This is why we chose face-to-face interviews. About $30 \mathrm{~min}$ of face-to-face interviews were taken for each individual. Moreover, the supervisors affiliated with the survey company trained the interviewers to implement the CE survey as persuasively and effectively as possible. Table 1 shows these attributes and how each of the levels of the attributes was defined. 
Table 1. Descriptions and levels of the chosen attributes.

\begin{tabular}{|c|c|c|}
\hline Attributes & Descriptions & Levels \\
\hline Habitat loss & $\begin{array}{l}\text { Ratio of land degradation and habitat } \\
\text { loss }\end{array}$ & $\begin{array}{l}\text { Level 1: } 0 \% p^{\#} \\
\text { Level 2: } 5 \% \text { p } \\
\text { Level 3: } 10 \% p \\
\text { Level 4: } 20 \% p\end{array}$ \\
\hline Landscape destruction & Percentage of decrease natural beauty & $\begin{array}{l}\text { Level 1: } 0 \% p^{\#} \\
\text { Level 2: } 5 \% \text { p } \\
\text { Level 3: } 10 \% p \\
\text { Level 4: } 20 \% p\end{array}$ \\
\hline Hazardous materials & $\begin{array}{l}\text { The degree of release of hazardous } \\
\text { materials in manufacturing } \\
\text { and operating }\end{array}$ & $\begin{array}{l}\text { Level 1: } 0 \% p^{\#} \\
\text { Level 2: } 5 \% \text { p } \\
\text { Level 3: } 10 \% p \\
\text { Level 4: } 20 \% p\end{array}$ \\
\hline Light pollution & The degree of light pollution & $\begin{array}{l}\text { Level 1: } 0 \% p^{\#} \\
\text { Level 2: } 5 \% \mathrm{p} \\
\text { Level 3: } 10 \% \mathrm{p} \\
\text { Level 4: } 20 \% \mathrm{p}\end{array}$ \\
\hline Price & $\begin{array}{l}\text { Increase in monthly electricity bill per } \\
\text { household for alleviating environmental } \\
\text { damage in photovoltaic (PV) power } \\
\text { plants (unit: Korean won) }\end{array}$ & $\begin{array}{c}\text { Level 1: } 0^{\#} \\
\text { Level 2: } 500 \\
\text { Level 3: } 2000 \\
\text { Level 4: } 4000 \\
\text { Level 5: } 7000\end{array}$ \\
\hline
\end{tabular}

Notes: " indicates the status quo level of each attribute. USD 1.0 was approximately equal to KRW 1158.4 at the time of the survey.

\subsection{Design of Choice Sets}

A key problem encountered in a $\mathrm{CE}$ is information overload, that is, there are too many alternatives with too many complex attributes. Thus, for instances where there are too many alternatives, a data-generating process is essential. This process will rely on carefully designed choice tasks that help reveal the factors that influence the choice. In designing a $\mathrm{CE}$, it is important to define the attribute space (including the attributes and the range) with care, such that it includes the portion that is relevant for the policy questions being asked. Furthermore, CE involves the use of statistical design theory to construct choice sets that yield coefficient estimates that are not confounded by other factors [34]. Among various designs, such as the C-optimal, D-optimal and efficient designs, we used the orthogonal main effects design, which is effective at obtaining solely individual effects in the choice sets. The ability to incorporate this orthogonality is an important advantage over the revealed preference random utility models, in which, in reality, attributes are often found to be highly correlated with one another [29]. The orthogonal main effects design was implemented using the SPSS 12.0 package [35].

The orthogonal main effect designs allow the estimation of the part-worths for all main effects. Interactions, where the part-worth of a level of one factor depends on the level of another factor, are assumed to be negligible. These designs are attractive to researchers because they are usually quite small in size even when the number of the attributes and their levels is considerably high [36]. Moreover, they can avoid multicollinearity between the attributes and allow a consistent estimation of the effect of all attributes independently of each other. The coefficients estimated using such designs are generally characterized by minimum variance [37].

The CE questionnaire was comprised of two mitigation alternatives and a status quo alternative. We had a sequence of $4^{4} \times 5$ alternative groups in order to make each choice set. Consequently, there were $4^{2} \times 4^{2} \times 4^{2} \times 4^{2} \times 5^{2}$ possible combinations of attributes and levels to form the choice sets. However, since it was impractical to ask respondents to choose from all combinations, we narrowed 
this number down to sixteen alternatives, resulting in four selections for each person. Each choice set comprises three alternatives: alternatives $\mathrm{A}$ and $\mathrm{B}$, and the status quo alternative. Thus, we can make eight choice sets and group them into two blocks. Each block has four choice sets. The respondents were randomly allocated to one of the two blocks. Thus, we provided each respondent with four choice sets and demanded the choice of one alternative among the three within each choice set.

Each respondent was asked to select one of three alternatives four times. Figure 1 is an example of choice card we present to the respondents. This is an example of the choice card we present during the survey. After they read the description of each attribute with visual cards, they look the card over and compare three alternatives including status quo. The final step is to choose A, B, or Status quo.

\begin{tabular}{|c|}
\hline \multicolumn{1}{|c|}{ Habitat loss } \\
\hline Landscape destruction \\
\hline Hazardous materials \\
\hline \multicolumn{1}{|c|}{ Light pollution } \\
\hline \multicolumn{1}{|c|}{ Additional monthly } \\
electricity bill per household \\
\hline $\begin{array}{l}\text { Check with } \sqrt{ } \text { the only } \\
\text { available alternative that you } \\
\text { prefer among Alternative } \mathrm{A}, \\
\text { B or the status quo. }\end{array}$ \\
\hline
\end{tabular}

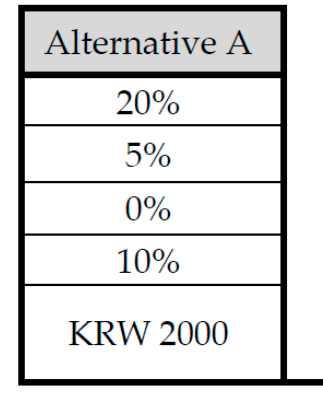

$\square$

A

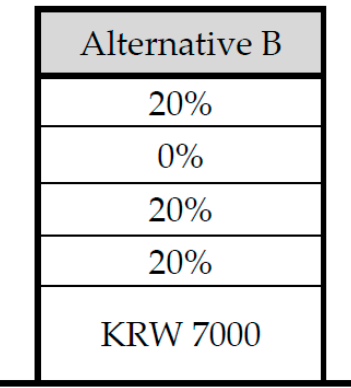

$\square$

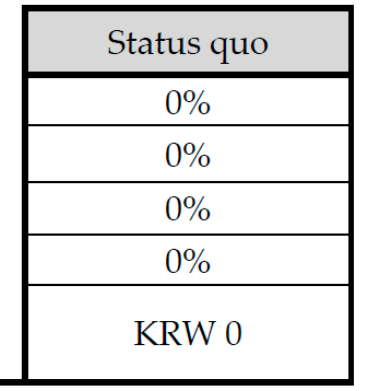

$\square$

Status quo

Figure 1. A sample choice set used in this study.

\subsection{Questionnaire and Survey}

We prepared a survey questionnaire with the assistance of experts at a polling firm and tested it with a focus group to see how well potential respondents understood the questions. The final version reflected the inputs of the focus group as well as the advice provided by the experts at the polling firm who were assigned to organize the fieldwork.

The survey instrument consists of three parts. The first is an introductory section, explaining the general background information on PV power plants to the respondents and then familiarizing respondents with the attributes of the impact of PV power plants. To enhance respondents' understanding, a color photograph of a process of operation and environmental damages of PV power plants was inserted into this section. The second part contained $C E$ analysis questions that were designed to elicit respondents' WTP for mitigating damage of PV power plants by estimating trade-offs between price and other attributes. The final part contains questions relating to the households' socioeconomic variables.

This study is the first that uses a CE for evaluating the economic costs of environmental damage caused by PV power plants. Hence, it was not clear whether the respondents had fully understood the trade-offs between price and other attributes of the environmental damage described in the scenario. Therefore, we conducted person-to-person interviews where we gave detailed questions to respondents in order to obtain higher response rates. To derive the respondents' reliable and responsible decision making, 20- to 65-year-old heads of households were selected and interviewed in the CE survey.

The survey was conducted for a month from 1 June 2016. The post-interview follow-up telephone check was done to reduce the number of skipped questions and to verify the results of the survey, both of which tend to increase the reliability of our data. Besides obtaining answers for the skipped variables, a total of 1300 observations verified that the CE survey was properly conducted. We asked by phone whether the interviewer performed their job properly, whether the interviewers used the visual aids properly, and whether the respondents sufficiently understood the CE questions. We also checked 
the consistency of the respondent's answers by asking several questions again. Perhaps remarkably, respondents in Korea understood the CE questions easily with the help of the interviewer.

In the process of verification, 300 observations from the original total of 1300 interviewed were removed from the sample. For some observations, we could find no one by the given name at the telephone number given by the respondent. For some questionnaires, the answers given over the phone were inconsistent with the answers given in the interview. For some survey results, there were skipped variables that cannot be made up over the phone. Some respondents frankly confessed that they did not pay attention to the CE survey. Some observations were evaluated to be of poor quality by the interviewers. Finally, we obtained 1000 useable observations.

Two points concerning the survey should be investigated. First, given that only 1000 households were chosen, we check whether this number is sufficient to make useful conclusion or not. According to Arrow et al. [38], 1000 useable observations are enough for researchers to derive a statistically acceptable and representative conclusion. To the best of the authors' knowledge, this study employs bigger sample size than other applied CE studies found in the literature. Moreover, as explained above, we asked each respondent four questions. Thus, the actual number of observations is 4000 , which is definitely not small. Second, whether the interviewee having no any concept and knowledge of PV system before the survey could give a reliable response or not should be also examined. In this regard, the trained interviewers provided the interviewees with many visual aids such as color pictures describing the PV system easily and explained them persuasively in the field survey. Judging from the interviewers' comments, the respondents could understand the PV system without any great difficulty. Therefore, it does not seem that the sample size and/or the respondents without prior knowledge about PV systems hinder us from making a reliable conclusion.

\section{The Model}

\subsection{Random Utility Model}

The random utility model is a well-known model in CE studies. In this study, we obtained the respondents' choices from three available alternatives; a multinomial logit (MNL) model [39] was adopted. The random utility model explains the consumer's utility in the form of an indirect utility function. The indirect utility function $\left(I_{i j}\right)$ is divided into two parts: a deterministic part, $D_{i j}$, and a stochastic part, $e_{i j}$.

$$
I_{i j}=D_{i j}\left(X_{i j}, C_{i}\right)+e_{i j}
$$

where $X_{i j}$ has the attributes in alternative $j$ and $C_{i}$ is the characteristic set of the respondent $i$.

The respondent $i$ who chooses alternative $j$ from choice set $S_{i}$ gains more utility than he or she does from choosing another alternative $k$; that is, $I_{i j}>I_{i k}$ for $j \neq k$ in $S_{i}$. His or her probability can be written as:

$$
\operatorname{Pr}\left(j \mid S_{i}\right)=\operatorname{Pr}\left(D_{i j}+e_{i j}>D_{i l}+e_{i l}\right)=\operatorname{Pr}\left(D_{i j}-D_{i l}>e_{i l}-e_{i j}\right) .
$$

If the unobservable effects $e_{i j}$ are independently and identically distributed with a Type I extreme value distribution, the probability is:

$$
\operatorname{Pr}\left(j \mid S_{i}\right)=\frac{\exp \left(D_{i j}\right)}{\sum_{l \in S_{i}} \exp \left(D_{i l}\right)} .
$$

Each respondent answers with the preferred alternative among the four choice sets. Each choice set consists of the status quo alternative and three other alternatives; $j$ ranges from 1 to 4 . Now we have a data of the respondents' indirect utility function. The equations have different values depending on their choice $(j)$. As mentioned above, we showed four types of choice cards to the respondents; thus indirect function changes according to the type. This is why the indirect utility functions have a 
subscribe $i$ and $j$, which means indirect utility function has different value from the respondent $i$ and the alternative $j$.

To obtain the estimates of parameters, we applied the MNL model. It constructs the log-likelihood function which includes the deterministic part, $D_{i j}$, of the indirect utility function. When $y_{i j}$ is a dummy variable for a chosen alternative and $N$ is the total number of respondents, the log-likelihood function is given by:

$$
\ln L=\sum_{i=1}^{N} \sum_{j=1}^{3}\left(y_{i j} \ln \left[\operatorname{Pr}\left(j \mid S_{i}\right)\right]\right)
$$

To analyze the above function, we used maximum likelihood (ML) estimation which finds out parameters to maximize the $\log$-likelihood function. Note that $\operatorname{Pr}\left(j \mid S_{i}\right)$ is a function of parameters $\beta$ and regressors $X$ and $y_{i j}$ takes 1 only as the respondents choose $j$ [40]. The first-order conditions for the ML estimation are:

$$
\frac{\partial L}{\partial \beta}=\sum_{i=1}^{N} \sum_{j=1}^{3} \frac{y_{i j}}{\operatorname{Pr}\left(j \mid S_{i}\right)} \frac{\partial \operatorname{Pr}\left(j \mid S_{i}\right)}{\partial \beta}=0_{i j}
$$

\subsection{WTP Model}

As mentioned above, the deterministic part $\left(D_{i j}\right)$ of the indirect utility function is explained by the attributes $X_{i j}$. We set up the attributes in a linear functional form. The attribute vector is defined as follows: $\left(X_{1}, X_{2}, X_{3}, X_{4}, X_{5}\right)=$ (Decrease in habitat loss, Abatement of landscape destruction, Reduction of hazardous materials, Decline in light pollution, and Price). An alternative-specific constant (ASC) was added to the deterministic part to estimate the effect of a missed series of attributes [41].

$$
D_{i j}=A S C_{j}+\beta_{1} X_{1, i j}+\beta_{2} X_{2, i j}+\beta_{3} X_{3, i j}+\beta_{4} X_{4, i j}+\beta_{5} X_{5, i j}
$$

By differentiating $D_{i j}$ with respect to $X_{i j}$, MWTP is given by:

$$
\begin{aligned}
& M W T P_{Z_{1}}=-\left(\partial D / \partial X_{1}\right) /\left(\partial D / \partial X_{5}\right)=-\beta_{1} / \beta_{5} \\
& M W T P_{Z_{2}}=-\left(\partial D / \partial X_{2}\right) /\left(\partial D / \partial X_{5}\right)=-\beta_{2} / \beta_{5} \\
& M W T P_{Z_{3}}=-\left(\partial D / \partial X_{3}\right) /\left(\partial D / \partial X_{5}\right)=-\beta_{3} / \beta_{5} \\
& M W T P_{Z_{4}}=-\left(\partial D / \partial X_{3}\right) /\left(\partial D / \partial X_{5}\right)=-\beta_{4} / \beta_{5}
\end{aligned}
$$

The $\beta^{\prime}$ s are the estimated coefficients of each attribute, and the combinations in Equation (7) represent the trade-off between the price and each attribute. They can also be interpreted as the marginal rate of substitution between them.

\section{Results}

\subsection{Estimation Results}

Table 2 presents the estimation results. We introduce ASC to capture the average effect on utility of unobserved factors in the model. There are three places to insert ASC; if we have three ASCs we have a problem in interpreting it. To prevent this, normally at most $(n-1)$ ASC can be entered when $J$ alternatives are presented. In this paper, we included one ASC in the model. Only status quo alternative have ASC, which means reference to other alternatives.

All the coefficient estimates are statistically significant at the $10 \%$ level. Moreover, their signs are consistent with our expectation. Four of the attributes (except for price) have positive coefficient estimates, indicating that those are valuable for the respondents. Therefore, people are more likely to agree to pay a certain bid amount if this would mitigate those environmental damages. Unlike the signs of the other attributes, the sign of the price coefficient is negative and statistically significant: the higher the price, the lower the probability that respondent $i$ will select the alternative. It is natural that a higher payment lowers the utility, which implies that the survey was reasonably implemented. 
Table 2. Estimation results of the multinomial logit model.

\begin{tabular}{|c|c|c|}
\hline Variables $^{a}$ & Coefficient Estimates $b$ & $t$-Values \\
\hline $\mathrm{ASC}^{\mathrm{c}}$ & -0.886 & $-1.85^{\#}$ \\
\hline Habitat loss & 0.297 & $6.50^{\#}$ \\
\hline Landscape destruction & 0.117 & $2.55^{\#}$ \\
\hline Hazardous materials & 0.268 & $5.74^{\#}$ \\
\hline Light pollution & 0.348 & $6.96^{\#}$ \\
\hline Price & -0.220 & $-11.44^{\#}$ \\
\hline Number of observations & \multicolumn{2}{|c|}{4000} \\
\hline Log-likelihood & \multicolumn{2}{|c|}{-4312.31} \\
\hline Wald statistic d ( $p$-value) & \multicolumn{2}{|c|}{$149.35^{\#}(0.000)$} \\
\hline
\end{tabular}

Notes: ${ }^{a}$ The variables are defined in Table $1 .{ }^{\mathrm{b}, \#}$ indicates statistical significance at the $10 \%$ level. ${ }^{\mathrm{c}}$ ASC refers to alternative-specific constant, which represents a dummy for the respondent choosing the status quo. ${ }^{d}$ The null hypothesis is that all the parameters are zero and the corresponding $p$-value is reported in parenthesis beside the statistic.

\subsection{MWTP Estimates of Each Attribute}

The MWTP calculated on the basis of Equation (7) are shown in Table 3. For example, WTP for a one percentage point decrease in habitat loss can be calculated from the equation $-0.297 /(-0.220)$ by hand regardless of its standard error. The monthly MWTP for one percentage point decrease in habitat loss is KRW 135 (USD 0.12). Its t-value was computed as 7.82, indicating that the MWTP value is significantly different from zero at the $1 \%$ level. The monthly MWTP for one percentage point decrease of habitat loss was computed as KRW 135 (USD 0.12). Similarly, the MWTPs for one percentage point abatement of landscape destruction, for one percentage point reduction of hazardous materials and for one percentage point decline in light pollution were KRW 53 (USD 0.05), KRW 122 (USD 0.11) and KRW 158 (USD 0.14), respectively. The MWTPs for these three attributes are significant at the $1 \%$ level.

Table 3. Estimation results of the marginal willingness to pay (MWTP) per month per household.

\begin{tabular}{cccc}
\hline Attributes & MWTP $^{\mathbf{a}}$ & $\boldsymbol{t}$-Values & 95\% Confidence Intervals \\
\hline Habitat loss (unit: \%p) & $\begin{array}{l}\text { KRW 135 * } \\
\text { (USD 0.12) }\end{array}$ & 7.82 & $\begin{array}{c}\text { KRW 101 to 170 } \\
\text { (USD 0.09 to 0.15) }\end{array}$ \\
\hline Landscape destruction (unit: \%p) & $\begin{array}{l}\text { KRW 53* } \\
\text { (USD 0.05) }\end{array}$ & 2.62 & $\begin{array}{c}\text { KRW 12 to 94 } \\
\text { (USD 0.01 to 0.08) }\end{array}$ \\
\hline Hazardous materials (unit: \%p) & $\begin{array}{l}\text { KRW 122 * } \\
\text { (USD 0.11) }\end{array}$ & 6.78 & $\begin{array}{c}\text { KRW 85 to 156 } \\
\text { (USD 0.07 to 0.13) }\end{array}$ \\
\hline Light pollution (unit: \%p) & $\begin{array}{l}\text { KRW 158 * } \\
\text { (USD 0.14) }\end{array}$ & 7.47 & $\begin{array}{c}\text { KRW 116 to 203 } \\
\text { (USD 0.10 to 0.18) }\end{array}$ \\
\hline
\end{tabular}

Notes: ${ }^{\text {a }}$ The unit is Korean won per month. USD 1.0 was approximately equal to KRW 1158.4 from the average of the exchange rates in June 2016. Refer to Korea Exchange Bank [42]. ${ }^{\mathrm{b}}$ The $t$-values are computed by the use of the delta method. * indicates statistical significance at the $1 \%$ level.

The importance of the four attributes can be inferred from a comparison of their MWTPs. The MWTP result does not of itself reveal the importance level, but instead indicates the increase in WTP. Arranging these values in ascending order reveals their relative importance. People believed that a one percentage point decline in light pollution is more significant than others, because the MWTPs for a one percentage point decline in light pollution was higher than other three attributes. This is probably because people want to avoid light pollution more than habitat loss, landscape destruction and the release of hazardous materials. However, people are less sensitive to landscape destruction.

We report the confidence intervals for the MWTP of each attribute, rather than its point estimates only, in order to allow for the uncertainty involved in the MWTP estimates [43] and to lessen the risk of errors; point estimates have a high error risk. Since a report on interval information reduces the 
probability of an incorrect prediction, it is more reliable and beneficial for use in a development policy for the weather forecast service. In this paper, we used the Monte Carlo simulation method [44] to obtain 95\% confidence intervals for the MWTPs. The MWTPs for the four attributes and their 95\% confidence intervals are shown in Table 3.

This result also can be interpreted in terms of environmental cost. As previously stated, we can measure environmental cost by computing WTP. Therefore, the environmental costs of a one percentage point increase in habitat loss, landscape destruction, hazardous materials, and light pollution caused by PV power plants are estimated to be KRW 135 (USD 0.12), 53 (0.05), $122(0.11)$, and 158 (0.14), respectively, per household per month. These results are interpreted as follows in the case of MWTP: people are most concerned about light pollution and are most insensitive to landscape destruction.

\subsection{Scenarios for Environmental Costs of PV Power Plants}

Policy implications can be drawn from various scenarios for environmental costs that are combinations of these attributes. In the same way as before, the environmental costs of the scenarios were assessed by calculating MWTPs of the attributes. This application uses the power of the CE method to overcome the changeability of policy planning. We were able to compute the environmental cost for the proposed scenarios and rank these, and thus prioritize the scenario with the highest environmental cost. This ranking helps to evaluate the environmental costs of each potential scenario, even though it contains preliminary information.

This study considers three scenarios for environmental damage caused by PV power plants. Scenario A is a situation where the worst habitat loss, slight landscape destruction and light pollution occurs. Scenario B is a situation where the worst hazardous materials, slight habitat loss and light pollution arises. Scenario $C$ is a situation where the worst light pollution, slight landscape destruction and hazardous materials happens. In each scenario, a total of $35 \%$ point of environmental destruction occurs. The specification of the scenarios and the resulting environmental costs are indicated in Table 4.

Table 4. Scenarios for environmental costs (EC) of PV power plants.

\begin{tabular}{cccc}
\hline Attributes & Scenario A & Scenario B & Scenario C \\
\hline Habitat loss & $20 \% \mathrm{p}$ & $5 \% \mathrm{p}$ & $0 \% \mathrm{p}$ \\
\hline Landscape destruction & $5 \% \mathrm{p}$ & $0 \% \mathrm{p}$ & $10 \% \mathrm{p}$ \\
\hline Hazardous materials & $0 \% \mathrm{p}$ & $20 \% \mathrm{p}$ & $5 \% \mathrm{p}$ \\
\hline Light pollution & $10 \% \mathrm{p}$ & $10 \% \mathrm{p}$ & $20 \% \mathrm{p}$ \\
\hline Monthly EC & KRW 4545 & KRW 4695 & KRW 4300 \\
per household & (USD 3.92) & (USD 4.05) & KRW 51,600 \\
\hline Yearly EC & KRW 54,540 & KRW 56,340 & (USD 48.64) \\
per household & (USD 47.08) & KRW 1086 billion & KRW 995 billion \\
\hline \multirow{2}{*}{ Aggregate value per year } & $\begin{array}{c}\text { KRW 1052 billion } \\
\text { (USD 908 million) }\end{array}$ & (USD 938 million) & (USD 859 million) \\
\hline \multirow{2}{*}{ 95\% confidence intervals } & KRW 750 to 1365 billion & KRW 779 to 1388 billion & KRW 663 to 1338 billion \\
& (USD 647 to 1179 million) & (USD 672 to 1199 million) & (USD 572 to 1155 million) \\
\hline
\end{tabular}

Note: USD 1.0 is approximately equal to KRW 1158.4, which was the average of the exchange rates in Jun 2016. Refer to Korea Exchange Bank [37].

The detailed calculation process is as follows. For scenario A, the monthly environmental cost of increasing in habitat loss by 20 percentage points is KRW 2700 (USD 2.3), that is, 20 times KRW 135 (USD 0.11). The monthly environmental cost of increasing in landscape destruction, increasing in hazardous materials and increasing in light pollution, are calculated in the same way. Other things being equal, a household's monthly environmental costs for Scenarios A, B, and C are KRW 4545 (USD 3.92), KRW 4695 (USD 4.05), and KRW 4300 (USD 3.71), respectively. A household's annual environmental costs are about KRW 54,540 (USD 47.08), KRW 56,340 (USD 48.64), and KRW 51,600 (USD 44.54), respectively. The total costs for each scenario are obtained from a simple computation. 
Calculating the aggregate value for a certain scenario is helpful in predicting the resulting public costs. Measuring and comparing the aggregate value of the various scenarios is useful in choosing between many scenarios.

The annual environmental cost for all households in South Korea was calculated by multiplying the annual environmental costs by the number of households in 2016. According to Statistics Korea, the number is $19,284,671$. The last row of Table 4 shows the total environmental costs for each scenario. As a result, scenario B had the highest cost, followed by Scenarios A and C in order. Hence, Scenario $\mathrm{B}$ should be avoided if other conditions are identical in each scenario. Scenario analysis is excellent for determining investment efficiency. Moreover, the scenarios are customizable and flexible, so this analysis is easily applied to the evaluation of environmental costs.

\section{Concluding Remarks}

South Korean government has vowed to boost the power supply from clean and renewable energy sources while pushing to wean the country off nuclear and coal-fired plants. Among them, PV power plants will increase greatly. Various studies have been conducted regarding the WTP and social externality for PV power. However, the environment and energy policies should be determined very carefully because there is room for concern about negative circumstances of the environment and human life. Moreover, no research about the environmental cost caused by PV power plants has been carried out. For this reason, we assessed the environmental costs by estimating WTP for mitigating environmental damage.

This study aimed to provide quantitative information on the environmental costs in South Korea to assist policymakers in determining the most effective investment level for renewable energy policy. To this end, CE and the MNL model were applied. In detail, the marginal value of improving each attribute of the South Korean was estimated, and the environmental cost of potential scenarios was calculated. Overall, the survey was relatively successful in eliciting MWTP values for reducing multiple types of environmental damage that would result from the PV power plants. Respondents were able to choose an alternative from a given choice set. Further, the MWTP estimates were statistically different from zero.

The monthly MWTP for one percentage point decrease of habitat loss was computed as KRW 135 (USD 0.12). Similarly, the monthly MWTPs for one percentage point abatement of landscape destruction, for one percentage point reduction of hazardous materials, and for one percentage point decline in light pollution were KRW 53 (USD 0.05), KRW 122 (USD 0.11) and KRW 158 (USD 0.14), respectively. Moreover, this result also can be interpreted in terms of environmental cost. These results imply that people are most concerned about the light pollutions and are most insensitive to landscape destruction. The expected total environmental cost of the scenarios for a PV power plants that provided five percentage points increase in habitat loss, 20 percentage points increase in hazardous materials, and 10 percentage points increase in light pollution was approximately KRW 1.09 trillion (USD 0.94 billion). Moreover, our study results suggest that the public is willing to shoulder additional taxes to mitigate environmental damage.

This study provides insight for both research and policymaking. From a research perspective, this study demonstrates the feasibility of extending the application of CEs, at least to valuing the environmental damage that is caused by PV power plants. This study is significant in that it is the first study ever to apply the CE to measure the environmental costs that result from PV power plants. From a policymaking perspective, this study provides useful information to policymakers for the development and implementation of more appropriate policies to deal with the environmental damage that is caused by PV power plants. It also illustrates that there is a substantial non-market MWTP for mitigating the multiple types of environmental damage that are caused by PV power plants and that respondents place differing values on the changes in attributes. Lastly, the results from this study provide a useful framework for incorporating such quantitative information for evaluating various policies with regard to the plans under consideration for PV power plants. 
Acknowledgments: This work was supported by the Korea Institute of Energy Technology Evaluation and Planning (KETEP) and the Ministry of Trade, Industry \& Energy (MOTIE) of the Republic of Korea (No. 20164030201060).

Author Contributions: All the authors contributed immensely. Hee-Jong Yang designed the ideas and analyzed the data; Seul-Ye Lim wrote the majority of the manuscript; and Seung-Hoon Yoo contributed the main idea and various scientific insights and helped to edit the manuscript.

Conflicts of Interest: The authors declare no conflict of interest.

\section{References}

1. United Nations Environment Programme, BASE. Environmental Due Diligence (EDD) of Renewable Energy Projects: Guidelines for Solar Photovoltaic Energy System; United Nations Environment Programme, BASE: Nairobi, Kenya, 2003.

2. Korea Environment Institute. Environmental Assessment and Environment-Friendly Development of Renewable Energy I: Photovoltaic and Wind Energy; Korea Environment Institute: Sejong, Korea, 2009.

3. Lamnatou, C.; Chemisana, D. Photovoltaic/thermal (PVT) systems: A review with emphasis on environmental issues. Renew. Energy 2017, 105, 270-287. [CrossRef]

4. Damon, T.; Vasilis, F. Environmental impacts from the installation and operation of large-scale solar power plants. Renew. Sustain. Energy Rev. 2011, 15, 3261-3270.

5. United Sates Department of Energy. Environmental Assessment for BP Solar Array Project Brookhaven National Laboratory Upton; United Sates Department of Energy: New York, NY, USA, 2009.

6. Tsoutsos, T.; Frantzeskaki, N.; Gekas, V. Environmental impacts from the solar energy technologies. Energy Policy 2005, 33, 289-296. [CrossRef]

7. National Renewable Energy Laboratory. Renewable Electricity Futures Study; National Renewable Energy Laboratory: Golden, CO, USA, 2012.

8. National Renewable Energy Laboratory. Best Research-Cell Efficiencies; National Renewable Energy Laboratory: Golden, CO, USA, 2006.

9. Horváth, G.; Kriska, G.; Malik, P.; Robertson, B. Polarized light pollution: A new kind of ecological photopollution. Front. Ecol. Environ. 2009, 7, 317-325. [CrossRef]

10. Száz, D.; Mihályi, D.; Farkas, A.; Egri, Á.; Barta, A.; Kriska, G.; Robertson, B.; Horváth, G. Polarized light pollution of matte solar panels: Anti-Reflective photovoltaics reduce polarized light pollution but benefit only some aquatic insects. J. Insect Conserv. 2016, 20, 663-675. [CrossRef]

11. Qi, L.; Zhang, Y. Effects of solar photovoltaic technology on the environment in China. Environ. Sci. Pollut. Res. 2017, 1-10. [CrossRef] [PubMed]

12. Ho, C.K.; Ghanbari, C.M.; Diver, R.B. Methodology to assess potential glint and glare hazards from concentrating solar power plants: Analytical models and experimental validation. J. Sol. Energy Eng. 2011, 133, 491-500. [CrossRef]

13. Ho, C.K. Relieving a glaring problem. Sol. Today 2013, 27, 28-31.

14. Zografakis, N.; Sifaki, E.; Pagalou, M.; Nikitaki, G.; Psarakis, V.; Tsagarakis, K.P. Assessment of public acceptance and willingness to pay for renewable energy sources in Crete. Renew. Sustain. Energy Rev. 2010, 14, 1088-1095. [CrossRef]

15. Abdullah, S.; Jeanty, P.W. Willingness to pay for renewable energy: Evidence from a contingent valuation survey in Kenya. Renew. Sustain. Energy Rev. 2011, 15, 2974-2983. [CrossRef]

16. Liu, W.; Wang, C.; Mol, A.P.J. Rural public acceptance of renewable energy deployment: The case of Shandong in China. Appl. Energy 2013, 102, 1187-1196. [CrossRef]

17. Navrud, S.; Bråten, G. Consumers' preferences for green and brown electricity: A choice modeling approach. Rev. Écono. Politique 2007, 117, 795-811. [CrossRef]

18. Scarpa, R.; Willis, K. Willingness to pay for renewable energy: Primary and discretionary choice of British households' for micro-generation technologies. Energy Econ. 2010, 32, 129-136. [CrossRef]

19. Gracia, A.; Barreiro-Hurlé, J.; Pérezy Pérez, L. Can renewable energy be financed with higher electricity prices? Evidence from a Spanish region. Energy Policy 2012, 50, 784-794. [CrossRef]

20. Cicia, G.; Cembalo, L.; Del Giudice, T.; Palladino, A. Fossil energy versus nuclear, wind, solar and agricultural biomass: Insights from an Italian national survey. Energy Policy 2012, 42, 59-66. [CrossRef] 
21. Lee, J.-S.; Yoo, S.-H. Measuring the environmental cost of tidal power plant construction: A choice experiment study. Energy Policy 2009, 37, 5069-5074. [CrossRef]

22. Garrod, G.D.; Willis, K.G. The non-use benefits of enhancing forest biodiversity: A contingent ranking study. Ecol. Econ. 1997, 21, 45-61. [CrossRef]

23. Ida, T.; Kinoshita, S.; Sato, M. Conjoint analysis of demand for IP Telephony: The case of Japan. Appl. Econ. 2008, 40, 1279-1287. [CrossRef]

24. Ida, T. Beyond Mobile number portability: Measuring consumer preferences for service portability in Japan's mobile phone market. Appl. Econ. 2012, 44, 3357-3369. [CrossRef]

25. Madden, G.; Simpson, M. Residential broadband subscription demand: An econometric analysis of Australian choice experiment data. Appl. Econ. 1997, 29, 1073-1078. [CrossRef]

26. Baarsma, B.E. The Valuation of the Ijmeer nature reserve using conjoint analysis. Environ. Resour. Econ. 2003, 25, 343-356. [CrossRef]

27. Banfi, S.; Filippini, M.; Horehájová, A. Using a choice experiment to estimate the benefits of a reduction of externalities in urban areas with special focus on electrosmog. Appl. Econ. 2012, 44, 387-397. [CrossRef]

28. Tarfasa, S.; Brouwer, R. Estimation of the public benefits of urban water supply improvements in Ethiopia: A choice experiment. Appl. Econ. 2013, 45, 1099-1108. [CrossRef]

29. Hanley, N.; Wright, R.E.; Adamowicz, W. Using choice experiments to value the environment. Environ. Resour. Econ. 1998, 11, 413-428. [CrossRef]

30. Johnson, F.R.; Desvousges, W.H. Estimating stated preferences with rated-pair data: Environmental, health, and employment effects of energy programs. J. Environ. Econ. Manag. 1997, 34, 79-99. [CrossRef]

31. Merino-Castello, A. Eliciting Consumers' Preferences Using Stated Preferencediscrete-Choice Models: Contingent Ranking Versus Choice Experiment; Working Paper No. 705; University Pompeu Fabra Economics and Business: Barcelona, Spain, 2003; Available online: http://www.econ.upf.edu/docs/papers/downloads/705.pdf (accessed on 23 September 2017).

32. Cuccia, T.; Cellini, R. Is cultural heritage really important for tourists? A contingent rating study. Appl. Econ. 2007, 39, 261-271. [CrossRef]

33. Kim, H.-Y.; Park, S.-Y.; Yoo, S.-H. Public acceptability of introducing a biogas mandate in Korea: A contingent valuation study. Sustainability 2016, 8, 1087. [CrossRef]

34. Yoo, S.-H.; Kwak, S.-J.; Lee, J.-S. Using a choice experiment to measure the environmental costs of air pollution impacts in Seoul. J. Environ. Manag. 2008, 86, 308-318. [CrossRef] [PubMed]

35. Statistical Package for the Social Sciences (SPSS). SPSS Conjoint 14.0; SPSS Inc.: Chicago, IL, USA, 2005.

36. Green, P.E. On the design of choice experiments involving multifactor alternatives. J. Consum. Res. 1974, 1, 61-68. [CrossRef]

37. Kuhfeld, W.F.; Tobias, R.D.; Garratt, M. Efficient experimental design with marketing research applications. J. Mark. Res. 1994, 31, 545-557. [CrossRef]

38. Arrow, K.; Solow, R.; Portney, P.R.; Leamer, E.E.; Radner, R.; Schuman, H. Report of the NOAA panel on contingent valuation. Fed. Regist. 1993, 58, 4601-4614.

39. McFadden, D. Conditional logit analysis of qualitative choice behavior. In Frontiers in Econometrics; Zarembka, P., Ed.; Academic Press: New York, NY, USA, 1973; pp. 105-140.

40. Cameron, A.C.; Trivedi, P.K. Microeconometrics: Methods and Applications; Cambridge University Press: New York, NY, USA, 2005.

41. Adamowicz, W.; Louviere, J.; Williams, M. Combining revealed and stated preference methods for valuing environmental amenities. J. Environ. Econ. Manag. 1994, 26, 271-292. [CrossRef]

42. Korea Exchange Bank. Available online: htt://www.kebhana.com (accessed on 8 August 2016).

43. Park, T.; Loomis, J.B.; Creel, M. Confidence intervals for evaluating benefits from dichotomous choice contingent valuation studies. Land Econ. 1991, 67, 64-73. [CrossRef]

44. Krinsky, I.; Robb, A.L. On approximating the statistical properties of elasticities. Rev. Econ. Stat. 1986, 68, 715-719. [CrossRef]

(C) 2017 by the authors. Licensee MDPI, Basel, Switzerland. This article is an open access article distributed under the terms and conditions of the Creative Commons Attribution (CC BY) license (http://creativecommons.org/licenses/by/4.0/). 